\title{
Short Trains of Theta Frequency Stimulation Enhance CA1 Pyramidal Neuron Excitability in the Absence of Synaptic Potentiation
}

\author{
Ann E. Fink ${ }^{1}$ and Thomas J. 0'Dell ${ }^{2}$ \\ ${ }^{1}$ Interdepartmental PhD Program for Neuroscience and 2Department of Physiology, David Geffen School of Medicine, University of California, Los Angeles, \\ Los Angeles, California 90095
}

\begin{abstract}
Although plasticity at excitatory synapses is widely studied as a mechanism for memory formation, less is known about the properties and mechanisms underlying activity-dependent changes in excitability. Using extracellular and intracellular recordings in hippocampal slices, we find that short trains (2-3 s) of Schaffer collateral fiber stimulation delivered at $5 \mathrm{~Hz}$ induce a robust and persistent increase in the excitability of CA1 pyramidal cells in the absence of synaptic potentiation. This change in excitability is input specific, NMDA receptor dependent, and is not accompanied by lasting changes in either inhibitory synaptic transmission or somatic excitability. Although many of these properties are similar to those seen in synaptic long-term potentiation (LTP), the increase in CA1 pyramidal cell excitability was not blocked by inhibitors of several protein kinases required for the induction of LTP by theta frequency stimulation. Instead, $5 \mathrm{~Hz}$ stimulation-induced changes in neuronal excitability were blocked by inhibitors of the protein phosphatase calcineurin. Together, our results suggest that very brief bouts of theta frequency synaptic activity induce a selective, persistent, and dendritically localized increase in CA1 pyramidal cell excitability that might have an important role in both information storage and metaplasticity.
\end{abstract}

\section{Introduction}

Long-term potentiation (LTP) of excitatory synaptic transmission in the CA1 region of the hippocampus is often accompanied by an increase in postsynaptic firing too large to be explained by the potentiation of EPSPs, a form of plasticity known as EPSPspike (E-S) potentiation (Bliss and Lomo, 1973; Andersen et al., 1980). Although E-S potentiation has been studied for many years, its molecular mechanisms remain poorly understood. Several studies indicate that a persistent decrease in feed-forward inhibitory synaptic transmission is responsible for E-S potentiation in the hippocampal CA1 region, either through a protein phosphatase $2 \mathrm{~B}$ (PP2B)-mediated (Lu et al., 2000) or a metabotropic glutamate receptor ( $\mathrm{mGluR}$ ) and endocannabinoid-dependent mechanism (Chevaleyre and Castillo, 2003, 2004). In contrast, other studies suggest that E-S potentiation arises from activity-dependent alterations in the intrinsic excitability of CA1 pyramidal cells (Hess and Gustafsson, 1990; Jester et al., 1995). Consistent with this possibility, a number of recent studies have found lasting activitydependent alterations in the activity of voltage-dependent ion channels in CA1 pyramidal cells (Frick et al., 2004; Fan et al.,

\footnotetext{
Received March 26, 2009; revised July 18, 2009; accepted July 30, 2009.

This work was supported by the National Science Foundation Grant 0543651 and National Institute of Mental Health Grant MH609197 (T.J.O.). A.E.F. was supported by National Research Service Award F31MH077442 from the National Institute of Mental Health. We are grateful to Dean Buonomano and Tiago Carvalho for comments and help with data analysis software.

Correspondence should be addressed to Dr. Thomas J. O'Dell, Department of Physiology, David Geffen School of Medicine at University of Los Angeles, California, 53-231 Center for the Health Sciences, Box 951751, Los Angeles, CA 90095. E-mail: todell@mednet.ucla.edu.

DOI:10.1523/JNEUROSCI.1450-09.2009

Copyright $\odot 2009$ Society for Neuroscience $\quad 0270-6474 / 09 / 2911203-12 \$ 15.00 / 0$
}

2005; Xu et al., 2005; Campanac and Debanne, 2008). Finally, some evidence suggests that E-S potentiation is a circuit-level phenomenon arising from LTP-induced changes in the balance of excitatory and inhibitory inputs onto CA1 pyramidal cells (Abraham et al., 1987; Chavez-Noriega et al., 1989; Marder and Buonomano, 2004).

One explanation for the multitude of potential mechanisms underlying E-S potentiation is that different patterns of synaptic activity induce this form of plasticity by recruiting distinct postsynaptic signaling pathways. If so, it seems especially important to understand the mechanisms underlying the induction of E-S potentiation by patterns of neuronal activity similar to those found in vivo. One prominent pattern of neuronal activity seen in the hippocampus in vivo is the theta rhythm, a $4-12 \mathrm{~Hz}$ oscillation seen during certain behavioral states (Buzsáki, 2002). Importantly, single pulses of presynaptic fiber stimulation at theta frequency $(5 \mathrm{~Hz})$ elicit complex spike bursting in CA1 pyramidal cells (Thomas et al., 1998), an endogenous pattern of action potential firing seen in these cells in vivo (Ranck, 1973). Thus, because it mimics key features of in vivo patterns of hippocampal activity, we explored the ability of $5 \mathrm{~Hz}$ presynaptic fiber stimulation to induce $\mathrm{E}-\mathrm{S}$ potentiation in vitro.

Although induction of synaptic LTP by single pulses of $5 \mathrm{~Hz}$ stimulation typically requires trains lasting tens of seconds (Thomas et al., 1998), we find that just 2-3 s of single pulses delivered at $5 \mathrm{~Hz}$ induce robust and long-lasting E-S potentiation in the absence of synaptic LTP. Five hertz stimulation-induced E-S potentiation is input specific and requires activation of NMDA-type glutamate receptors but is insensitive to inhibitors of several protein kinases required for LTP. E-S potentiation is 
instead blocked by PP2B inhibitors. This form of E-S potentiation was not associated with lasting changes in inhibitory synaptic transmission or global changes in neuronal excitability. Together, our results demonstrate that very short trains of $5 \mathrm{~Hz}$ stimulation induce a novel form of $\mathrm{E}-\mathrm{S}$ potentiation in hippocampal CA1 pyramidal cells.

\section{Materials and Methods}

Hippocampal slice preparation. Standard methods approved by the University of California, Los Angeles Institutional Animal Care and Use Committee were used to prepare $400-\mu \mathrm{m}$-thick hippocampal slices from 8- to 16-week-old male C57BL/6 mice (Charles River Laboratories). Animals were anesthetized using halothane and killed by cervical dislocation, and brains were then removed and placed in cold $\left(4^{\circ} \mathrm{C}\right)$ artificial CSF (ACSF) containing the following (in $\mathrm{mm}$ ): $124.0 \mathrm{NaCl}, 25.0$ $\mathrm{NaHCO}_{3}, 4.4 \mathrm{KCl}, 1.0 \mathrm{NaH}_{2} \mathrm{PO}_{4}, 1.2 \mathrm{MgSO}_{4}, 10.0$ D-glucose, and 2.0 $\mathrm{CaCl}_{2}$. Transverse slices were cut from the isolated hippocampi using a manual tissue slicer (Stoelting) and maintained in an interface-type chamber (Fine Science Tools) continuously perfused $(2-3 \mathrm{ml} / \mathrm{min}$ ) with warm $\left(30-31^{\circ} \mathrm{C}\right)$, oxygenated $\left(95 \% \mathrm{O}_{2} / 5 \% \mathrm{CO}_{2}\right)$ ACSF. Slices were allowed to recover for at least $1 \mathrm{~h}$ before the start of an experiment.

Extracellular recordings. All electrophysiological recordings were conducted at $30-31^{\circ} \mathrm{C}$ in a submerged-style recording chamber. Bipolar, nichrome wire stimulating electrodes were used to activate Schaffer collateral/commissural (SC) fibers in the hippocampal CA1 region. Extracellular glass microelectrodes filled with ACSF (resistance, 5-10 M $\Omega$ ) were placed in the stratum radiatum to measure field (fEPSPs) and in the stratum pyramidale to measure population spikes (PSs). To ensure slice health, only slices with maximal fEPSP amplitudes $>4 \mathrm{mV}$ and maximal PS amplitudes $>5 \mathrm{mV}$ were used. For baseline recordings, stimulation strength was adjusted to produce a $1 \mathrm{mV}$ PS (basal stimulation rate, 0.02 $\mathrm{Hz}$ ). When picrotoxin was included in the ACSF, $\mathrm{KCl}$ was reduced to 2.4 $\mathrm{mM}, \mathrm{MgSO}_{4}$ and $\mathrm{CaCl}_{2}$ concentrations were both elevated to $4.0 \mathrm{~mm}$, and the $\mathrm{CA} 3$ region was removed from slices.

For experiments testing input specificity, two stimulating electrodes were placed in stratum radiatum, one near the border of CA1 with the CA3 region and the second near the border of CA1 with the subiculum, to activate independent groups of SC fibers. Pathway independence was confirmed by the absence of paired-pulse facilitation when a stimulation pulses delivered to one pathway was followed $50 \mathrm{~ms}$ later by a stimulation pulse delivered to the second pathway. Baseline recordings were obtained by alternately stimulating the two pathways every $30 \mathrm{~s}$ (each pathway was stimulated once per minute). After obtaining a $20 \mathrm{~min}$ baseline, one pathway received a train of $5 \mathrm{~Hz}$ stimulation.

Whole-cell current-clamp recordings. All whole-cell recordings were conducted in hippocampal slices lacking the CA3 region to reduce spontaneous EPSPs and to reduce bursting when inhibition was blocked with picrotoxin. Whole-cell current-clamp recordings were performed using patch electrodes (3-6 M $\Omega$ ) filled with the following (in mM): 146 potassium gluconate, $7.0 \mathrm{KCl}, 10.0 \mathrm{HEPES}, 1.0 \mathrm{EGTA}, 0.1 \mathrm{CaCl}_{2}, 4.0 \mathrm{Mg}$-ATP, and 0.3 Na-GTP, pH 7.3. Internal osmolarity was between 289 and 294 mOsm, and external was $\sim 300-305$ mOsm. Reported voltages are not corrected for an $\sim 11 \mathrm{mV}$ liquid junction potential estimated for this electrode solution using pClamp (Molecular Devices). Consistent with previous reports, we found that these concentrations of ATP, GTP, $\mathrm{Ca}^{2+}$, and EGTA as well as osmolarity were crucial for maintaining stable measures of EPSPs (Hagiwara and Irisawa, 1989; Velumian and Carlen, 1999; Xu et al., 2005) and IPSPs (Chen et al., 1990). Cells with resting membrane potentials (RMPs) less negative than $-58 \mathrm{mV}$ were discarded, and the quality of the recording was further confirmed by the ability of the cell to fire an action potential of $>100 \mathrm{mV}$ in amplitude, measured from the RMP. Constant injections of depolarizing or hyperpolarizing current were used to maintain the cells at a membrane potential of approximately $-60 \mathrm{mV}$. Throughout each recording, 50-ms-long pulses of hyperpolarizing $(-0.1 \mathrm{nA})$ current were delivered after synaptic stimulation to monitor the stability of input and series resistance. Recordings with unstable membrane potentials or series resistance $>40 \mathrm{M} \Omega$ were discarded.
Data acquisition and analysis. AxoClamp 2B and AxoPatch 1A amplifiers were used for both extracellular and whole-cell current-clamp recordings. In some experiments, an IX2-700 amplifier from Dagan was used for extracellular recordings. Signals were low-pass filtered at $2 \mathrm{kHz}$ and digitized at $10 \mathrm{kHz}$. Data acquisition and analysis were performed using either the Experimenter's Workbench/Common Processing software package from DataWave Technologies or pClamp. Programs written using MATLAB (MathWorks) were also used to analyze somatic excitability and EPSP spike curves obtained from intracellular recordings. Unless indicated otherwise, two-tailed independent $t$ tests were used to compare data between two groups, and two-tailed paired $t$ tests were used to compare data within a group (i.e., before and after $5 \mathrm{~Hz}$ stimulation).

Analysis of somatic excitability. Several standard parameters (Bekkers and Delaney, 2001; Cudmore and Turrigiano, 2004; Marder and Buonomano, 2004; Xu et al., 2005) were measured to examine pyramidal cell excitability using somatic whole-cell current-clamp recordings. In these experiments, four $250 \mathrm{~ms}$ current pulses $10 \mathrm{~s}$ apart were injected first in increasing order $(-0.1,0.05,0.1$, and $0.2 \mathrm{nA})$ and then in decreasing order. Values obtained from the responses elicited by the same current injection were averaged. Input resistance was measured using the hyperpolarizing $(-0.1 \mathrm{nA})$ current pulse and latency to first spike, spike firing threshold, and number of spikes fired were measured from responses elicited by depolarizing current pulses. The firing threshold was defined as the membrane potential at spike initiation where $d V / d t=15 \mathrm{mV} / \mathrm{ms}$ (slightly modified from Bekkers and Delaney, 2001; Cudmore and Turrigiano, 2004); this criterion was also used to detect spikes. Reliable spike detection was obtained by setting the condition that $d V / d t$ must increase over three sampling points after spike initiation.

Construction of intracellular E-S curves and analysis. Data for E-S curves were obtained by using weak presynaptic fiber stimulation intensities that evoked small EPSPs eliciting $0 \%$ probability of firing $\left(P_{\mathrm{f}}\right)$ and then gradually increasing the stimulation strength until obtaining $100 \%$ $P_{\mathrm{f}}$ (Daoudal et al., 2002; Marder and Buonomano, 2003, 2004; Staff and Spruston, 2003). Generally, 10 EPSPs were evoked at each stimulation strength (interpulse interval, $10 \mathrm{~s}$.). To ensure a good curve fit, however, it was important to obtain reliable upper $\left(P_{\mathrm{f}}=100 \%\right)$ and lower $\left(P_{\mathrm{f}}=\right.$ $0 \%)$ asymptotes as well as sufficient middle points for the curve. Because of this, we sometimes delivered more pulses at given stimulation strengths to obtain sufficient data points for a complete E-S curve. In initial experiments, we also monitored E-S coupling in a control pathway that did not receive $5 \mathrm{~Hz}$ stimulation. For dual-pathway recordings, each pathway was stimulated five times at each stimulation strength, $10 \mathrm{~s}$ apart, alternating between pathways. Stimulating electrode placement and determination of input specificity were similar to the protocol described for extracellular recordings.

To construct E-S curves, slopes of EPSPs (initial $1 \mathrm{~ms}$ of the rising slope) were plotted against spike firing activity, coded as either 1 (fires) or 0 (failure to fire). An illustration can be seen in Figure 6. These data were then entered into a custom-written MATLAB program (Marder and Buonomano, 2004), which (1) divided EPSP slopes into 12 equally sized bins ranging from the lowest EPSP slope value to the highest, (2) averaged EPSP slopes and firing probability for each of the 12 bins, and (3) fitted the resulting EPSP versus spike point plot with a two-parameter sigmoid curve using the following function: $S(x)=1 /\left(1+\exp \left[\left(E_{50}-\right.\right.\right.$ $x) / k]$ ). The two free variables in the function are the $E_{50}$ value (EPSP slope corresponding to $50 \%$ firing probability) and $k$, which represents the inverse of the sigmoid slope. $E_{50}$ values were used to assess changes in neuronal excitability.

For recordings of EPSPs and IPSPs between E-S curves, we obtained a 3 min baseline of EPSP/IPSP pairs at a constant stimulation strength before $5 \mathrm{~Hz}$ stimulation (basal stimulation frequency, $0.05 \mathrm{~Hz}$ ), continued to record for $5 \mathrm{~min}$ after $5 \mathrm{~Hz}$ stimulation, and again recorded EPSP/IPSP pairs at the same stimulation strength for $5 \mathrm{~min}$ between the second and third E-S curves (15-20 min after $5 \mathrm{~Hz}$ stimulation). For analysis, we measured the first $1 \mathrm{~ms}$ of the EPSP rising slope and measured IPSP amplitude from the maximal hyperpolarization in the first 50 ms after EPSP initiation (Lu et al., 2000). 

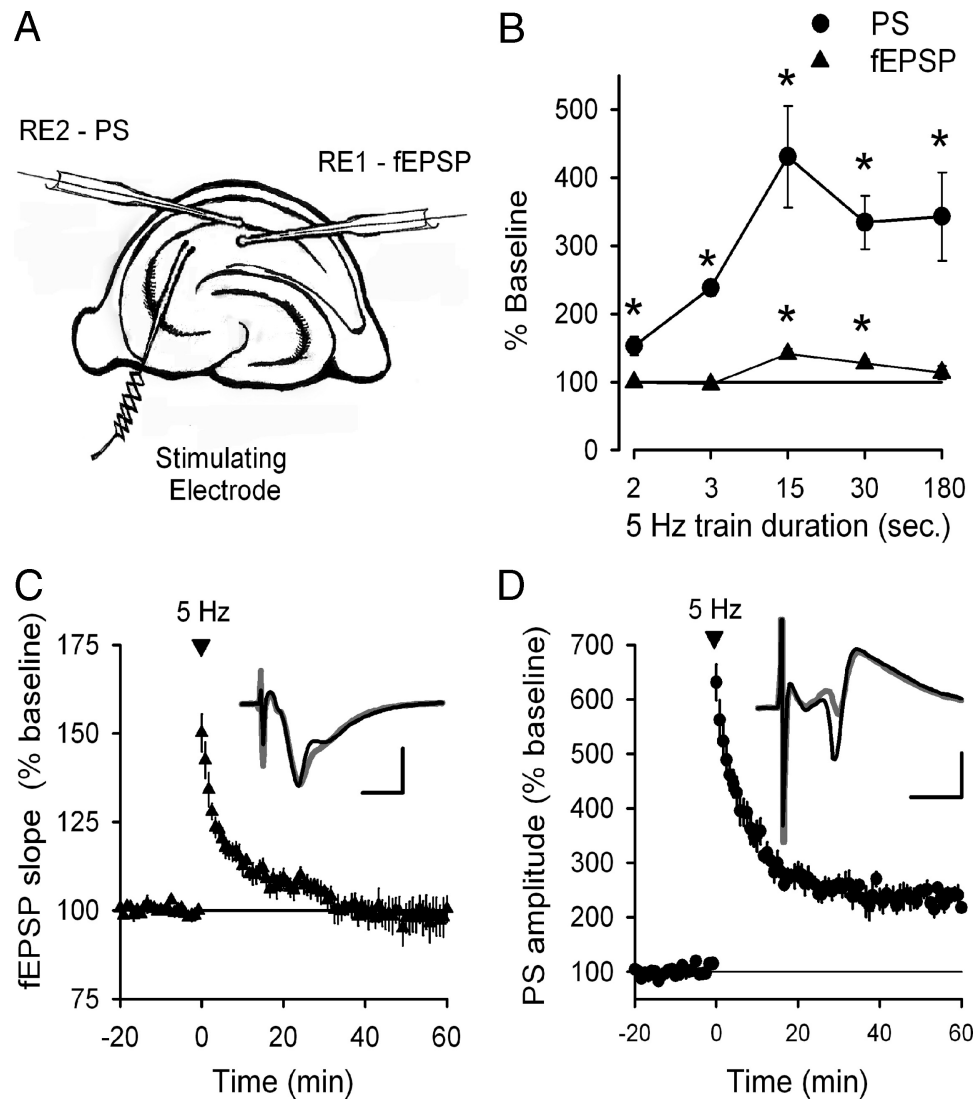

Figure 1. Short trains of $5 \mathrm{~Hz}$ stimulation induce robust E-S potentiation in the absence of synaptic LTP. $\boldsymbol{A}$, Schematic of hippocampal slice showing placement of stimulating and recording electrodes (RE). $\boldsymbol{B}$, Changes in synaptic strength (triangles) and PS amplitudes (circles) induced by different durations of $5 \mathrm{~Hz}$ stimulation. Note that, although PS amplitudes were significantly enhanced by all trains of $5 \mathrm{~Hz}$ stimulation, only 15 and 30 s trains of $5 \mathrm{~Hz}$ induce significant synaptic LTP. Points correspond to the mean \pm SEM percentage of baseline values at $60 \mathrm{~min}$ after $5 \mathrm{~Hz}$ stimulation $\left({ }^{*} p<0.01 ; n=6-8\right)$. $C, \boldsymbol{D}$, Three seconds of $5 \mathrm{~Hz}$ stimulation (delivered at time $=0$ ) has no lasting effect on synaptic strength $(\boldsymbol{C})$ but induces a significant potentiation of PS amplitude (D). The insets show examples of fEPSPs and PS recorded from the same slice before (gray) and 60 min after (black) $3 \mathrm{~s}$ of $5 \mathrm{~Hz}$ stimulation. Calibration: $5 \mathrm{~ms}, 2 \mathrm{mV}$.

Reagents. D-Amino-phosphonovaleric acid (D-APV) was obtained from Ascent Scientific. U0126 [1,4-diamino-2,3-dicyano-1,4-bis $(o-$ aminophenylmercapto)butadiene], H89 ( $N$-[2-( $p$-bromo-cinnamylamino)ethyl]-5-isoquinoline-sulfon-amide $2 \mathrm{HCl}$ ), staurosporine, and FK-506 were obtained from LC Laboratories. LY341495 [(2S)-2-amino-2-[(1S,2S)-2carboxycycloprop-1-yl]-3-(xanth-9-yl) propanoic acid], cyclosporin A, wortmannin, and the calcineurin autoinhibitory peptide (CnIP) were obtained from Tocris Biosciences. All other compounds were obtained from Sigma-Aldrich. Slices were incubated in kinase and phosphatase inhibitors for at least $1 \mathrm{~h}$ before delivery of $5 \mathrm{~Hz}$ stimulation.

\section{Results}

Brief trains of presynaptic fiber stimulation at the theta frequency can induce a robust and lasting PS potentiation in the absence of synaptic LTP

We used dual extracellular recordings to examine the effects of 5 $\mathrm{Hz}$ stimulation ranging in duration from $2 \mathrm{~s}$ to $3 \mathrm{~min}$ on both fEPSPs and PS in the CA1 region (Fig. 1A). Consistent with previous findings (Thomas et al., 1996, 1998), the induction of synaptic LTP by single pulses of $5 \mathrm{~Hz}$ stimulation showed an "inverted U"-shaped dependence on train duration, i.e., significant potentiation of fEPSPs was only observed after 15-30 s of stimulation (Fig. 1B), whereas shorter (2-3 s) or longer (3 min) trains had no lasting effect on synaptic strength. Surprisingly, the effects of $5 \mathrm{~Hz}$ stimulation on PS amplitudes exhibited a strikingly different dependence on duration of stimulation. As shown in Figure $1 B$, PS amplitudes were significantly potentiated by trains of $5 \mathrm{~Hz}$ stimulation that had no lasting effect on synaptic strength. For example, although $3 \mathrm{~s}$ of $5 \mathrm{~Hz}$ stimulation had no lasting effect on excitatory synaptic transmission (60-min post-5 Hz stimulation fEPSPs were $98 \pm 5 \%$ of baseline, $n=6$ ) (Fig. $1 C)$, this duration of stimulation induced a significant and persistent increase in PS amplitude (60-min post- $5 \mathrm{~Hz}$ stimulation PS amplitudes were increased to $241 \pm$ $10 \%$ of baseline) (Fig. 1D). Moreover, although synaptic LTP diminished as the duration of $5 \mathrm{~Hz}$ stimulation was increased to $3 \mathrm{~min}$ (fEPSPs were $113 \pm 9 \%$ of baseline $60 \mathrm{~min}$ post- $5 \mathrm{~Hz}$ stimulation, $n=7$ ) (Fig. $1 B$ ), this pattern of synaptic stimulation still induced robust potentiation of PS amplitudes (PS amplitudes were increased to $339 \pm 67 \%$ of baseline) (Fig. $1 B$ ). Together, these results show that some $5 \mathrm{~Hz}$ stimulation protocols can induce a "pure" form of E-S potentiation, i.e., long-term increases in PS amplitude in the absence of synaptic LTP. Importantly, this not only indicates that E-S potentiation and synaptic LTP are distinct forms of plasticity but also provides a way to study the mechanisms of E-S potentiation in isolation. Three seconds of $5 \mathrm{~Hz}$ stimulation, which reliably induced an approximately twofold potentiation of PS amplitudes with no change in the fEPSP slope (Fig. 1C,D), was used in subsequent experiments to study the properties and mechanisms underlying theta frequency stimulation-induced E-S potentiation.

Stimulation at $5 \mathrm{~Hz}$ induces an NMDA receptor-dependent and input-specific form of $\mathrm{E}-\mathrm{S}$ potentiation

To begin to investigate the cellular mechanisms underlying $5 \mathrm{~Hz}$ stimulation-induced E-S potentiation, we first examined the potential role of NMDA receptors in the induction of this form of E-S potentiation. Consistent with a previous study showing that the induction of E-S potentiation requires NMDA receptor activation ( $L u$ et al., 2000), the induction of E-S potentiation by $3 \mathrm{~s}$ of $5 \mathrm{~Hz}$ stimulation was significantly inhibited in slices bathed in ACSF containing the NMDA receptor antagonist D-APV. As shown in Figure $2 \mathrm{~A}$, in the presence of $50 \mu \mathrm{M}$ D-APV, $3 \mathrm{~s}$ of $5 \mathrm{~Hz}$ stimulation had relatively little lasting effect on PS amplitudes (PS amplitudes were potentiated to $136 \pm 7 \%$ of baseline in APV-treated slices, $n=5$, compared with $234 \pm 32 \%$ of baseline in interleaved control experiments, $n=7 ; p<0.05)$. Although this indicates that NMDA receptor activation is required for $5 \mathrm{~Hz}$ stimulation-induced E-S potentiation, PS amplitudes were still significantly potentiated compared with pre-5 $\mathrm{Hz}$ baseline in slices treated with $50 \mu \mathrm{M}$ APV $(p<0.05)$. This residual potentiation was still present even in slices bathed in a higher concentration of D-APV $(100 \mu \mathrm{M} ; 60$-min post-5 Hz stimulation PS amplitudes were $149 \pm 9 \%$ of baseline, $n=4 ; p<0.05$ compared with baseline). This suggests that NMDA receptor-independent processes may also contribute to $5 \mathrm{~Hz}$ stimulation-induced PS 

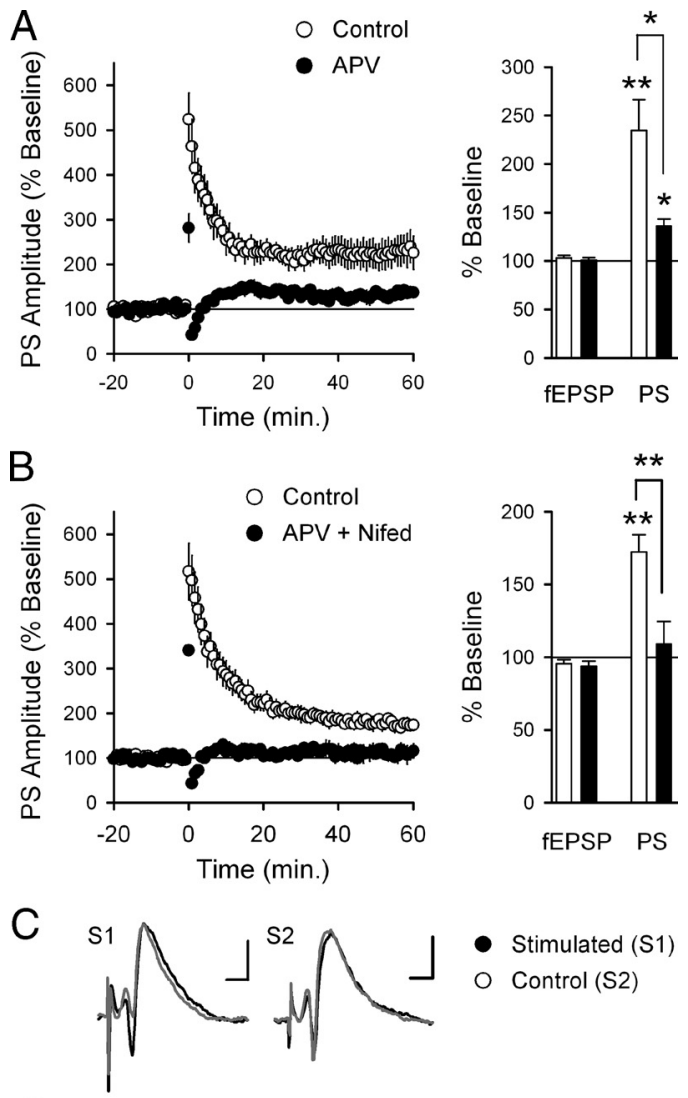

- Stimulated (S1) Control (S2)
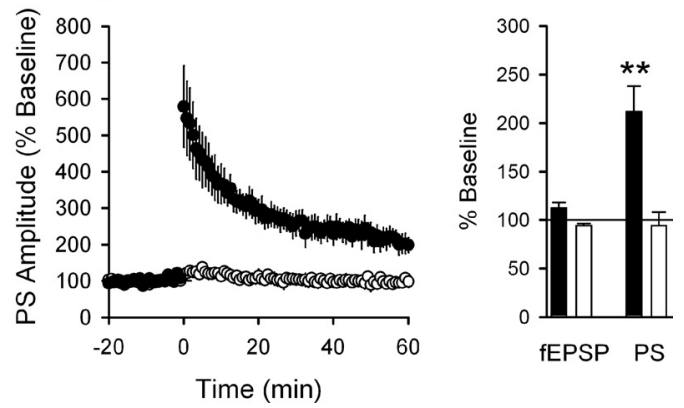

Figure 2. Five hertz stimulation-induced $\mathrm{E}-\mathrm{S}$ potentiation is NMDA receptor dependent and input specific. $A$, Left, A 3 s train of $5 \mathrm{~Hz}$ stimulation induced a persistent increase in PS amplitude in controls (open symbols; $n=7$ ) that was reduced in slices continuously bathed in ACSF containing $50 \mu \mathrm{m}$ D-APV (filled symbols; $n=5$ ). Right, Histogram showing fEPSP slopes and PS amplitude recorded $60 \mathrm{~min}$ after $5 \mathrm{~Hz}$ stimulation in control slices (open bars) and slices bathed in $50 \mu \mathrm{m}$ D-APV (filled bars). $\boldsymbol{B}$, Left, E-S potentiation induced by $3 \mathrm{~s}$ of $5 \mathrm{~Hz}$ stimulation is blocked in slices bathed in ACSF containing $50 \mu \mathrm{m}$ D-APV and $10 \mu \mathrm{m}$ nifedipine (60-min post- 5 $\mathrm{Hz}$ stimulation PS amplitudes were $109 \pm 15 \%$ of baseline; filled symbols; $n=5$ ). The open symbols show interleaved vehicle control experiments $(n=9)$ ). Right, Histogram showing fEPSP slopes and PS amplitudes recorded $60 \mathrm{~min}$ after $5 \mathrm{~Hz}$ stimulation in control slices (open bars) and slices bathed in ACSF containing nifedipine plus D-APV (filled bars). C, Left, Five hertz stimulation induces a pathway-specific potentiation of PS amplitudes. Dual stimulating electrodes were used to activate independent groups of presynaptic fibers. Five hertz stimulation delivered to one of these pathways (S1) induced significant PS potentiation (filled symbols), with no effect on the amplitude of PS evoked by the control pathway (S2; open symbols). The inset shows PS evoked in the same slice by the stimulated (S1, left) and control (S2, right) pathways before (gray) and $60 \mathrm{~min}$ after (black) $5 \mathrm{~Hz}$ stimulation. Calibration: $5 \mathrm{~ms}, 1 \mathrm{mV}$. Right, Summary of the effects of $3 \mathrm{~s}$ of $5 \mathrm{~Hz}$ stimulation on fEPSP and PS amplitude measured $60 \mathrm{~min}$ after $5 \mathrm{~Hz}$ stimulation. Five hertz stimulation induced a significant potentiation of PS in the stimulated pathway (filled bars; ${ }^{* *} p<0.01$ compared with baseline) but had no effect on PS amplitudes evoked by the control pathway (open bars; $p=0.508$ ). No significant change in the fEPSP was seen in either pathway. potentiation. Although some evidence suggests that mGluR activation might have an important role in $\mathrm{E}-\mathrm{S}$ potentiation (Breakwell et al., 1996; Chevaleyre and Castillo, 2003), blocking group I and group II mGluRs with $20 \mu \mathrm{M}$ LY341495 alone did not block 5 $\mathrm{Hz}$ stimulation-induced E-S potentiation $(n=3$; data not shown). We did observe, however, that the residual E-S potentiation that remained in the presence of D-APV was completely blocked in slices bathed in ACSF containing D-APV and the L-type calcium channel blocker nifedipine $(10 \mu \mathrm{M})$ (Fig. $2 B$ ) This suggests that activation of L-type calcium channels contributes to the induction of PS potentiation by $5 \mathrm{~Hz}$ stimulation. Bath application of nifedipine alone, however, had no significant effect on E-S potentiation (60-min post-3 s of $5 \mathrm{~Hz}$ stimulation PS amplitudes were $204 \pm 25 \%$ of baseline, $n=5$ in nifedipinetreated slices compared with $180 \pm 18 \%$ of baseline in interleaved vehicle control slices, $n=6 ; p=0.41$ ).

NMDA receptors require coincident presynaptic and postsynaptic activity for activation and thus allow the induction of plasticity that is local to the activated synapses, an important property of synaptic LTP. Our observation that $5 \mathrm{~Hz}$ stimulation-induced $\mathrm{E}-\mathrm{S}$ potentiation is dependent on NMDA receptor activation thus led us to investigate whether the E-S potentiation also exhibits input specificity. To examine this, we used two stimulating electrodes to activate independent groups of SC fiber inputs onto CA1 pyramidal cells and, after obtaining a $20 \mathrm{~min}$ baseline, delivered $3 \mathrm{~s}$ of $5 \mathrm{~Hz}$ stimulation to just one group of fibers. As shown in Figure $2 C$, the stimulated pathway exhibited strong E-S potentiation (60-min post- $5 \mathrm{~Hz}$ stimulation PS amplitudes were potentiated to $212 \pm 26 \%$ of baseline, $n=6$ ), whereas the control pathway remained unchanged (PS amplitudes were $94 \pm 13 \%$ of baseline). These results indicate that $5 \mathrm{~Hz}$ stimulation-induced E-S potentiation does not involve cell-wide changes in excitability but instead involves cellular changes restricted to regions near the stimulated synaptic inputs.

\section{E-S potentiation induced by $5 \mathrm{~Hz}$ stimulation is dependent on protein phosphatase activation}

Like synaptic LTP, our results indicate that the induction of E-S potentiation by $5 \mathrm{~Hz}$ stimulation protocols is NMDA receptor dependent. Thus, we next investigated whether several of the protein kinases known to be important for synaptic LTP might also be involved in $5 \mathrm{~Hz}$ stimulation-induced $\mathrm{E}-\mathrm{S}$ potentiation. Previous studies have found that synaptic LTP induced by $30 \mathrm{~s}$ of $5 \mathrm{~Hz}$ stimulation requires activation of protein kinase A (PKA) (Thomas et al., 1996; Makhinson et al., 2006), extracellular signal regulated kinase 1/2 (ERK1/2) (Winder et al., 1999; Watabe et al., 2000; Opazo et al., 2003), and phosphatidylinositol 3 (PI3) kinase (Opazo et al., 2003). We therefore first examined whether these protein kinases have a role in $5 \mathrm{~Hz}$ stimulation-induced $\mathrm{E}-\mathrm{S}$ potentiation. As shown in Figure 3, $A$ and $B$, the induction of E-S potentiation by $3 \mathrm{~s}$ of $5 \mathrm{~Hz}$ stimulation was not altered in slices bathed in ACSF containing the PKA inhibitor H89 $(10 \mu \mathrm{M})$ or the mitogen-activated protein kinase kinase (MEK) inhibitor U0126 $(20 \mu \mathrm{M})$. Even the broad-spectrum protein kinase inhibitor staurosporine, which inhibits a number of different protein kinases, including most isoforms of protein kinase $\mathrm{C}$ and calcium/ calmodulin-dependent kinase II (CaMKII) (Ling et al., 2002), had no effect on $5 \mathrm{~Hz}$ stimulation-induced E-S potentiation (60min post- $5 \mathrm{~Hz}$ stimulation PS amplitudes were potentiated to $214 \pm 41 \%$ of baseline in slices bathed in ACSF containing $1 \mu \mathrm{M}$ staurosporine, $n=5$, compared with $188 \pm 15 \%$ of baseline in interleaved vehicle control slices, $n=5$ ) (Fig. $3 C$ ). The PI3 kinase inhibitor wortmannin $(200 \mathrm{~nm})$ also had no effect on $5 \mathrm{~Hz}$ 

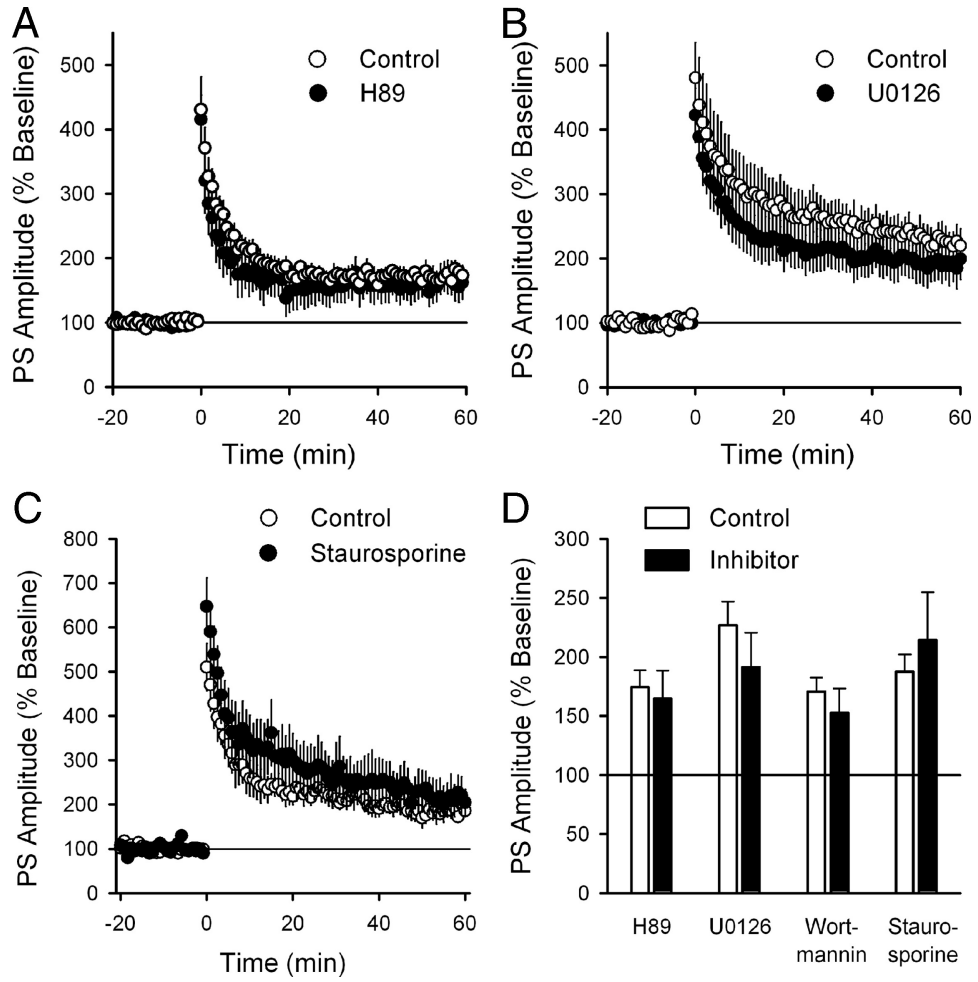

Figure 3. E-S potentiation induced by $3 \mathrm{~s}$ of $5 \mathrm{~Hz}$ stimulation is not blocked by protein kinase inhibitors. $\boldsymbol{A}$, The PKA inhibitor $\mathrm{H} 89(10 \mu \mathrm{M})$ has no effect on E-S potentiation. Sixty-minutes post-5 Hz stimulation PS amplitudes were potentiated to $174 \pm$ $15 \%$ of baseline in vehicle control slices (open symbols; $0.2 \%$ DMSO; $n=7$ ) and were potentiated to $165 \pm 24 \%$ of baseline in slices bathed in ACSF containing H89 (filled symbols; $n=7)$. $\boldsymbol{B}$, The MEK inhibitor U0126 (20 $\mu \mathrm{M})$ also failed to block E-S potentiation. Post- $5 \mathrm{~Hz}$ stimulation PS amplitudes were potentiated to $227 \pm 20 \%$ of baseline in vehicle control experiments (open symbols; $0.2 \%$ DMSO; $n=6$ ) and were potentiated to $191 \pm 30 \%$ of baseline in slices pretreated with U0126 (filled symbols; $n=6)$. C, The broad-spectrum kinase inhibitor staurosporine $(1 \mu \mathrm{m})$ does not block E-S potentiation. Sixty-minutes post- $5 \mathrm{~Hz}$ stimulation PS amplitudes were potentiated to $227 \pm 20 \%$ of baseline in staurosporine-treated slices (filled symbols; $n=5$ ) compared with $191 \pm 30 \%$ of baseline in vehicle control slices (open symbols; $0.1 \%$ DMSO; $n=5$ ). $\boldsymbol{D}$, Summary of PS amplitudes $60 \mathrm{~min}$ after $5 \mathrm{~Hz}$ stimulation in the presence (open bars) and absence (filled bars) of protein kinase inhibitors.

post- $5 \mathrm{~Hz}$ stimulation PS amplitudes were $123 \pm 13 \%$ of baseline compared with $221 \pm 28 \%$ of baseline in interleaved vehicle control experiments; $p<0.01)$. Five hertz stimulation-induced E-S potentiation was also strongly inhibited in slices bathed in ACSF containing the PP2B inhibitor FK-506 compared with interleaved control experiments $(p<0.01)$ (Fig. $4 B$ ). Thus, E-S potentiation induced by $3 \mathrm{~s}$ of 5 $\mathrm{Hz}$ stimulation does not depend on activation of protein kinases involved in synaptic LTP but is instead dependent on protein phosphatase activity.

\section{E-S potentiation induced by $5 \mathrm{~Hz}$ stimulation is not attributable to long-term depression of inhibitory synaptic transmission}

In the absence of synaptic LTP, E-S potentiation can be explained by either an increase in intrinsic excitability or longterm depression at feedforward inhibitory synapses onto CA1 pyramidal cells (I-LTD). If I-LTD is responsible for $5 \mathrm{~Hz}$ stimulation-induced E-S potentiation, then blocking $\mathrm{GABA}_{\mathrm{A}}$ receptor-mediated inhibitory synaptic transmission should occlude the ability of $5 \mathrm{~Hz}$ stimulation to induce a potentiation of PS amplitudes (Andersen et al., 1980; Abraham et al., 1987; Chavez-Noriega et al., 1989). Thus, to determine whether I-LTD contributes to $5 \mathrm{~Hz}$ stimulation-induced $\mathrm{E}-\mathrm{S}$ potentiation, we examined the effects of $3 \mathrm{~s}$ of 5 $\mathrm{Hz}$ stimulation on $\mathrm{E}-\mathrm{S}$ potentiation in slices continuously bathed in ACSF con-

stimulation-induced E-S potentiation (Fig. 3D). These kinase inhibitors also had little, if any, effect on the small and transient changes in synaptic transmission induced by $5 \mathrm{~Hz}$ stimulation (supplemental Fig. 1, available at www.jneurosci.org as supplemental material). Thus, although $5 \mathrm{~Hz}$ stimulation-induced E-S potentiation is NMDA receptor dependent, it is not blocked by inhibitors of the protein kinases required for the induction of synaptic LTP by longer trains of $5 \mathrm{~Hz}$ stimulation. This not only indicates that distinct signaling mechanisms underlie $5 \mathrm{~Hz}$ stimulation-induced E-S potentiation and synaptic LTP but also suggests that the E-S potentiation is unlikely to involve changes in neuronal excitability or inhibitory synaptic transmission mediated by protein kinases.

Although the protein phosphatase PP2B is thought to be important for LTD at excitatory synapses (Mulkey et al., 1993, 1994), it is also thought to have an important role in the downregulation of inhibitory synaptic transmission in some forms of E-S potentiation (Lu et al., 2000). We therefore next examined whether PP2B is involved in $5 \mathrm{~Hz}$ stimulation-induced $\mathrm{E}-\mathrm{S}$ potentiation using the PP2B inhibitors cyclosporin A $(2.0 \mu \mathrm{M})$ and FK-506 $(20 \mu \mathrm{M})$. As shown in Figure $4 A$, the initial potentiation of PS amplitudes seen immediately after $5 \mathrm{~Hz}$ stimulation in cyclosporin A-treated slices ( $458 \pm 71 \%$ of baseline, $n=5$ ) was nearly identical to that seen in interleaved, vehicle control experiments ( $434 \pm 34 \%$ of baseline, $n=9$ ). However, PS amplitudes rapidly decayed to baseline levels in cyclosporin A-treated slices (60-min taining the $\mathrm{GABA}_{\mathrm{A}}$ receptor antagonist picrotoxin $(100 \mu \mathrm{M})$. As shown in Figure $5, A$ and $B$, blocking inhibitory synaptic transmission with picrotoxin abolished the induction of E-S potentiation by $3 \mathrm{~s}$ of $5 \mathrm{~Hz}$ stimulation (60-min post- $5 \mathrm{~Hz}$ stimulation PS amplitudes were $71 \pm 7 \%$ of baseline, $n=5$, compared with $243 \pm 44 \%$ of baseline in interleaved controls slices bathed in normal ACSF, $n=9$; $p<0.01)$. Although this finding is consistent with the notion that this form of plasticity is occluded by pharmacological blockade of inhibition and thus involves I-LTD, we also noticed that postsynaptic responses during the $5 \mathrm{~Hz}$ trains were strongly suppressed in picrotoxintreated slices. As shown in Figure 5, $C$ and D, PS amplitudes undergo a rapid and sustained facilitation (approximately sixfold) during the $3 \mathrm{~s}$ of $5 \mathrm{~Hz}$ stimulation in slices bathed in normal ACSF. In contrast, this facilitation of PS amplitudes during the $5 \mathrm{~Hz}$ stimulation train was completely absent in picrotoxin-treated slices. This suggests that blocking inhibitory synaptic transmission with picrotoxin might inhibit the induction of $5 \mathrm{~Hz}$ stimulation-induced $\mathrm{E}-\mathrm{S}$ potentiation rather than occlude its expression. In other words, blocking $\mathrm{GABA}_{\mathrm{A}}$ receptors might prevent the normal facilitation of PS during $5 \mathrm{~Hz}$ stimulation that provides the postsynaptic depolarization required for NMDA receptor activation and induction of E-S potentiation. We thus repeated these experiments in the presence of picrotoxin but increased the stimulation strength during $5 \mathrm{~Hz}$ stimulation (by doubling the duration of 
A

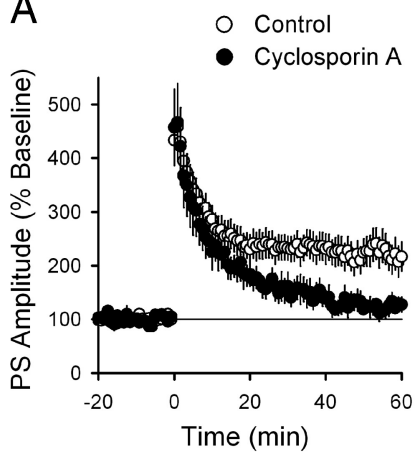

B CONTROL

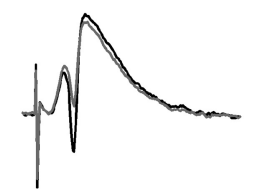

\section{FK-506}
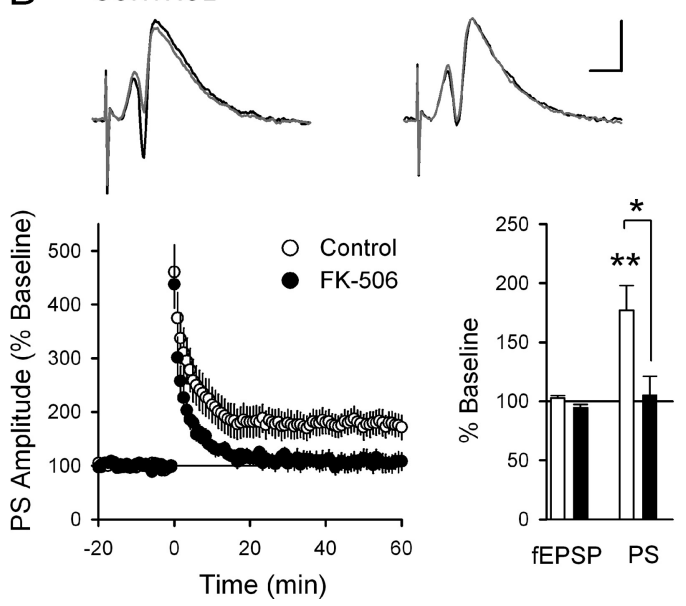

Figure 4. E-S potentiation induced by 3 s of $5 \mathrm{~Hz}$ stimulation is blocked by protein phosphatase inhibitors. A, Left, E-S potentiation induced by $3 \mathrm{~s}$ of $5 \mathrm{~Hz}$ stimulation is blocked by bath application of the calcineurin inhibitor cyclosporin A $(2 \mu \mathrm{m})$. Whereas control slices $(0.1 \%$ DMSO) showed a robust potentiation of PS amplitude (open symbols; $n=9$ ), no potentiation was observed in cyclosporin A-treated slices (filled symbols; $n=5$ ). Right, The histogram shows fEPSP slopes and PS amplitudes measured 60 min after $5 \mathrm{~Hz}$ stimulation in control (open bars) and cyclosporin A-treated (filled bars; ${ }^{* *} p<0.01$ compared with control) slices. $\boldsymbol{B}$, Left, Five hertz stimulation induced significant $P S$ potentiation in interleaved vehicle control experiments $(0.2 \% \mathrm{EtOH} ;$ open symbols; $n=12)$ but had no lasting effect on PS amplitudes in FK-506treated slices (filled symbols; $n=8$ ). Right, Histogram showing fEPSP slopes and PS amplitudes measured $60 \mathrm{~min}$ after $5 \mathrm{~Hz}$ stimulation in control (open bars) and cyclosporin A-treated (filled bars; ${ }^{*} p<0.05$ compared with control) slices. Inset, PS recorded from a control slice (left) and an FK-506-treated slice (right), before (gray) and $60 \mathrm{~min}$ after (black) $5 \mathrm{~Hz}$ stimulation. Calibration: $5 \mathrm{~ms}, 1 \mathrm{mV}$.

stimulation pulses) to produce larger PS amplitudes during the $5 \mathrm{~Hz}$ train. As shown in Figure 5, $C$ and $D$, increasing the stimulation strength during $5 \mathrm{~Hz}$ stimulation produced postsynaptic bursting and restored the induction of significant E-S potentiation in picrotoxin-treated slices (60-min post- 5 $\mathrm{Hz}$ stimulation PS amplitudes were potentiated to $163 \pm 24 \%$ of baseline, $n=5 ; p<0.05$ compared with baseline, $p=0.22$ compared with control) in the absence of any lasting change in the strength of excitatory synaptic transmission (Fig. 5A,B). Together, these experiments indicate that blocking inhibitory synaptic transmission with picrotoxin primarily inhibits the induction, rather than the expression, of $5 \mathrm{~Hz}$ stimulationinduced E-S potentiation. More importantly, although these results do not rule out a potential contribution of I-LTD in 5 $\mathrm{Hz}$ stimulation-induced E-S potentiation, they do suggest that this form of E-S potentiation is likely to involve longterm changes in intrinsic excitability.
Presynaptic $5 \mathrm{~Hz}$ stimulation paired with postsynaptic bursts of action potentials induces persistent input-specific increases in CA1 pyramidal cell excitability

To study the synaptic and/or neuronal changes responsible for 5 $\mathrm{Hz}$ stimulation-induced $\mathrm{E}-\mathrm{S}$ potentiation in more detail, we next used whole-cell current-clamp recordings to monitor synaptic transmission and neuronal excitability before and after $5 \mathrm{~Hz}$ stimulation. In these experiments, we first obtained intracellular measures of E-S coupling by measuring the probability of action potential firing elicited by EPSPs of different amplitudes and constructing an EPSP spike input-output curve (Daoudal et al., 2002; Staff and Spruston, 2003; Marder and Buonomano, 2004). EPSPs evoked by a $3 \mathrm{~s}$ train of $5 \mathrm{~Hz}$ stimulation were then paired with a burst of two to four action potentials elicited by a $30-\mathrm{ms}-$ long pulse of depolarizing current to mimic the EPSP-induced bursting that occurred during $5 \mathrm{~Hz}$ stimulation in our extracellular recording experiments (Fig. 5C). Input-output curves were constructed 5 and 20 min after pairing to determine whether $5 \mathrm{~Hz}$ stimulation paired with postsynaptic bursting induced a shift in EPSP-spike coupling (Fig. 6B). As shown in Figure 6, $C$ and $D$, the $E_{50}$ value corresponding to the EPSP slope that produced action potential firing $50 \%$ of the time showed a significant and input-specific decrease. In these experiments, $E_{50}$ values were decreased $0.5 \pm 0.2 \mathrm{mV} / \mathrm{ms} 20 \mathrm{~min}$ after pairing for EPSPs evoked by the pathway that received $5 \mathrm{~Hz}$ stimulation $(n=13 ; p<0.05$ compared with pre-pairing values) but were not significantly changed for an unstimulated pathway measured in the same cells $\left(E_{50}\right.$ shift $=+0.14 \pm 0.2 \mathrm{mV} / \mathrm{ms} ; p=0.51$ compared with pre-pairing values). The decrease in $E_{50}$ values after pairing indicates a higher probability of firing for a given EPSP slope and therefore an increase in excitability. The fact that E-S potentiation induced by pairing presynaptic $5 \mathrm{~Hz}$ stimulation with bursts of postsynaptic action potentials was not observed in an unstimulated pathway indicates that this form of plasticity requires coincident presynaptic and postsynaptic activity for induction. Furthermore, in a separate series of experiments, we found that pairing EPSPs evoked during a $3 \mathrm{~s}$ train of presynaptic $5 \mathrm{~Hz}$ stimulation with single postsynaptic action potentials failed to induce E-S potentiation (supplemental Fig. 2, available at www. jneurosci.org as supplemental material). This suggests that bursts of postsynaptic action potentials, rather than single spikes, are required to induce this form of $\mathrm{E}-\mathrm{S}$ potentiation. A summary showing the magnitude of the change in $E_{50}$ values produced in all of our control experiments in which EPSPs were paired with bursts of postsynaptic action potentials can be seen in supplemental Figure 3 (available at www.jneurosci.org as supplemental material).

We next examined whether the shift in $E_{50}$ values induced by pairing $5 \mathrm{~Hz}$ stimulation with postsynaptic bursting is also dependent on activation of PP2B. As seen in Figure 7A, the decrease in $E_{50}$ induced by pairing $3 \mathrm{~s}$ of $5 \mathrm{~Hz}$ stimulation with postsynaptic bursts of action potentials was completely blocked in slices bathed in ACSF containing the PP2B inhibitor FK-506 (20 $\mu \mathrm{M})$. Indeed, in the presence of FK-506, the pairing protocol induced a significant increase in $E_{50}$ values ( 20 min post-pairing values were increased by $0.64 \pm 0.24 \mathrm{mV} / \mathrm{ms}, n=7 ; p<0.05$ compared with pre-pairing values). FK-506 had no apparent effect on basal levels of excitability $(p=0.894)$, suggesting that the inhibition of pairing-induced E-S potentiation by $\mathrm{PP} 2 \mathrm{~B}$ inhibitors is not attributable to occlusion. To confirm that the E-S potentiation recorded in our experiments was dependent on postsynaptic calcineurin activation, we obtained E-S curves before and after pairing $3 \mathrm{~s}$ of $5 \mathrm{~Hz}$ stimulation with postsynaptic bursts in cells in 
A

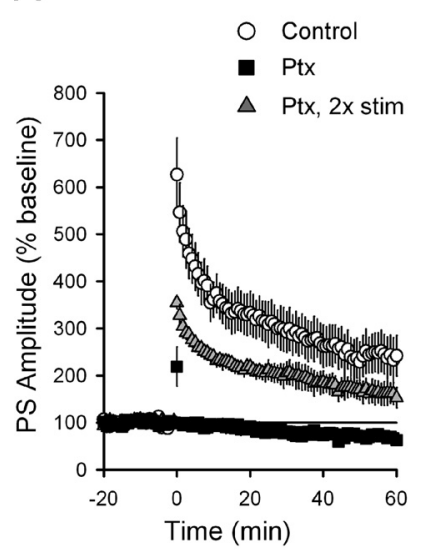

B

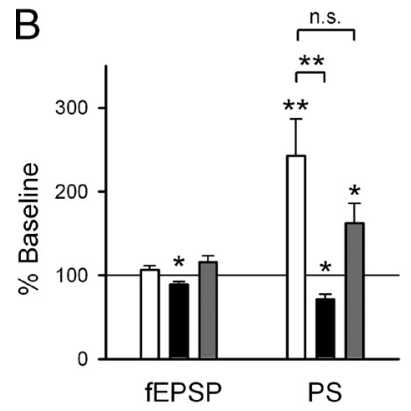

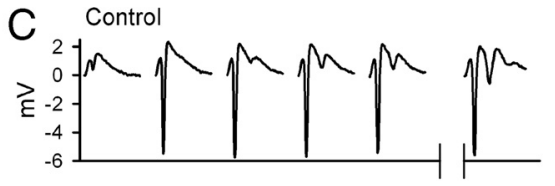
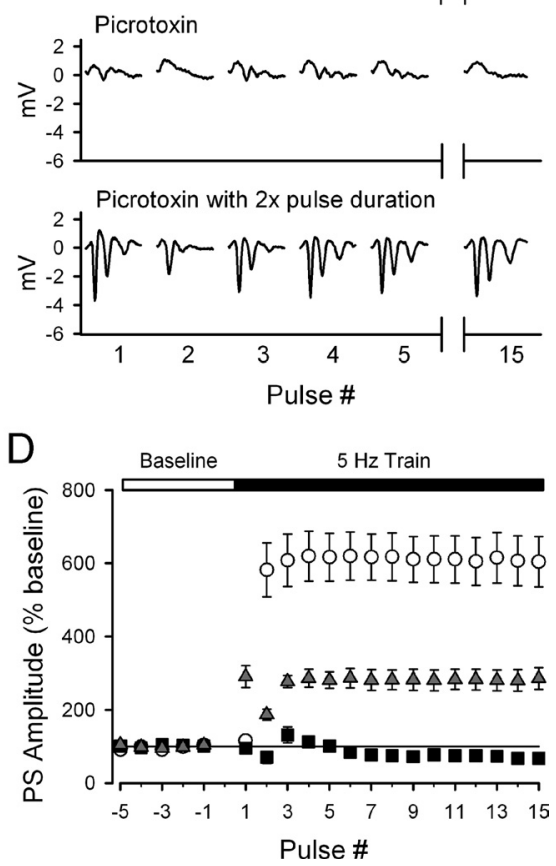

Figure 5. The induction, but not expression, of $5 \mathrm{~Hz}$ stimulation-induced $\mathrm{E}-\mathrm{S}$ potentiation is inhibited in picrotoxin-treated slices. $A$, Three seconds of $5 \mathrm{~Hz}$ stimulation at basal stimulation strength does not elicit $\mathrm{E}-\mathrm{S}$ potentiation in slices bathed in ACSF containing the $\mathrm{GABA}_{\mathrm{A}}$ receptor blocker picrotoxin (Ptx; $100 \mu \mathrm{m}$; squares; $n=5$ ), whereas robust $\mathrm{E}-\mathrm{S}$ potentiation was induced in interleaved control slices (circles; $n=9$ ). Significant $5 \mathrm{~Hz}$ stimulation-induced E-S potentiation was induced in picrotoxin-treated slices when stimulation intensity during $5 \mathrm{~Hz}$ stimulation was increased by doubling stimulation pulse duration during the train (triangles; $n=5$ ). $\boldsymbol{B}$, Summary of fEPSP slopes and PS amplitudes measured 60 min after $5 \mathrm{~Hz}$ stimulation in control slices (white bars), slices bathed in ACSF containing picrotoxin (black bars), and in the presence of picrotoxin in which the stimulation pulse duration was doubled during $5 \mathrm{~Hz}$ stimulation (gray bars). ${ }^{*} p<0.05,{ }^{* *} p<0.01$ compared with pre- $5 \mathrm{~Hz}$ stimulation baseline. C, Examples of PS elicited at different time points during $5 \mathrm{~Hz}$ stimulation in control slices (top), picrotoxin-treated slices (middle), and slices bathed in ACSF containing picrotoxin in which stimulation intensity was increased during the $5 \mathrm{~Hz}$ train (bottom). Each response is $25 \mathrm{~ms}$ in duration. Note that the facilitation of PS amplitude and bursting that occurs during $5 \mathrm{~Hz}$ stimulation in control slices is absent in picrotoxin-treated slices. D. Plot of percentage increase in PS amplitude during 15 pulses of $5 \mathrm{~Hz}$ stimulation in control slices, picrotoxin-treated slices, and slices exposed to picrotoxin in which stimulation pulse duration during $5 \mathrm{Hzstimulation}$ was doubled. Values are normalized to the last $5 \mathrm{~min}$ of baseline recordings.

which the CnIP (Lu et al., 2000) was delivered into the postsynaptic cell by including CnIP $(250 \mu \mathrm{M})$ in the recording electrode. For both control and CnIP cells, the pairing protocol was delivered at least $15 \mathrm{~min}$ after attaining the whole-cell configuration to allow diffusion of the peptide. As shown in Figure 7B, EPSP/burst pairing induced a significant E-S shift in interleaved control cells but had no effect in cells infused with CnIP. Unlike bath application of FK-506 (Fig. 7A), a pairing-induced increase in excitability was not observed in experiments in which PP2B was inhibited by postsynaptic delivery of CnIP (Fig. $7 B$ ). Although the reason for this difference is unclear, it may reflect differences in the effective levels of PP2B inhibition achieved with these different compounds and/or methods of delivery. In any event, our results suggest that activation of $\mathrm{PP} 2 \mathrm{~B}$ is required for the induction of E-S potentiation by $5 \mathrm{~Hz}$ EPSP/burst pairing.

We next examined the role of NMDA receptors in whole-cell recordings of E-S potentiation by pairing EPSPs with postsynaptic bursts of action potentials in the presence of bath-applied D-APV $(50 \mu \mathrm{M})$. As shown in Figure $7 C, E_{50}$ values were not significantly altered in cells were EPSP/burst pairing (15 pairs at $5 \mathrm{~Hz})$ was done in the presence of $50 \mu \mathrm{M}$ D-APV $(n=9 ; p=$

0.51 compared with pre-pairing baseline), whereas a significant shift was observed in interleaved control cells $(n=9$; $p<0.05$ compared with baseline). Although these data are consistent with the notion that NMDA receptor activation is required for pairing-induced $\mathrm{E}-\mathrm{S}$ potentiation, the magnitude of the $E_{50}$ shift in D-APV-treated cells was not significantly different from that seen in control cells (Fig. 7C). We thus repeated this experiment using a higher concentration of D-APV $(100 \mu \mathrm{M})$ and blocked L-type calcium channels with nifedipine (10 $\mu \mathrm{M})$. However, we again observed that the magnitude of the $E_{50}$ shift in D-APV/ nifedipine-treated cells was not statistically significant from that seen in control cells ( $n=5$ for each; data not shown). Thus, unlike the induction of E-S potentiation by $5 \mathrm{~Hz}$ stimulation alone (Fig. 2), the induction of E-S potentiation by EPSP/ spike pairing does not appear to be solely dependent on activation of NMDA receptors and/or L-type calcium channels. One possibility is that the burst of postsynaptic action potentials elicited in our pairing experiments leads to calcium influx via voltage-activated calcium channels that are not normally activated by $5 \mathrm{~Hz}$ stimulation alone.

Finally, because our extracellular recordings indicated that E-S potentiation is attributable to an increase in intrinsic excitability rather than I-LTD, we confirmed that the intracellularly recorded E-S shift is not attributable to a decrease in feedforward inhibition by constructing E-S curves before and after $3 \mathrm{~s}$ of $5 \mathrm{~Hz}$ stimulation paired with postsynaptic bursts in the presence of $100 \mu \mathrm{M}$ picrotoxin. As expected, basal excitability in the presence of picrotoxin was significantly enhanced compared with control experiments $(p<0.01)$. Despite this enhancement of basal excitability, the pairing protocol used in these experiments still induced significant E-S potentiation in the presence of picrotoxin (Fig. $7 D$ ). These results, like those from our experiments using extracellular recordings, indicate that $5 \mathrm{~Hz}$ stimulationinduced E-S potentiation is not primarily attributable to I-LTD.

\section{Presynaptic fiber stimulation at $5 \mathrm{~Hz}$ paired with bursts of postsynaptic action potentials does not lead to global increases in excitability or changes in IPSP amplitude}

The fact that $5 \mathrm{~Hz}$ stimulation-induced E-S potentiation is input specific, and therefore local, indicates that the induction of E-S potentiation with these stimulation protocols should not be associated with cell-wide changes in intrinsic excitability. To directly test this, we measured CA1 pyramidal cell excitability before, $5 \mathrm{~min}$ after, and $20 \mathrm{~min}$ after $3 \mathrm{~s}$ of EPSP/burst pairing at $5 \mathrm{~Hz}$. In these experiments, successive 250-ms-long current pulses at $-0.1,+0.05,+0.1$, and $+0.25 \mathrm{nA}$ were used to measure action potential firing threshold for the first spike, latency to first spike, and number of spikes fired for the positive current pulses 
and input resistance (for details, see $\mathrm{Ma}$ terials and Methods). As shown in Figure 8 , the pairing protocol had no effect on any of these parameters. EPSP/burst pairing also had no effect on mean membrane time constant, percentage sag of the membrane potential in response to hyperpolarizing current injection, or the current needed to maintain resting membrane potential (data not shown). There was, however, a small, but statistically significance ( $p<0.05)$, decrease in both AP amplitude $(-9 \pm 4 \%)$ and maximum $d V / d t$ $(-18 \pm 6 \%) 20 \mathrm{~min}$ after pairing. Importantly, similar changes in both of these parameters were also seen in experiments in which EPSPs were paired with a single postsynaptic action potential, a protocol that fails to induce a significant change in $E_{50}$ values (supplemental Fig. 2, available at www.jneurosci.org as supplemental material). This suggests that changes in these parameters are likely a result of prolonged whole-cell recording rather than a specific effect related to the increase E-S potentiation induced by EPSP/burst pairing.

Finally, we directly measured whether pairing EPSPs with bursts of postsynaptic action potentials had any effect on EPSPs and IPSPs (EPSPs from 13 cells and IPSPs from 8 cells) recorded in the periods between E-S curves (Fig. 9A). Consistent with the notion that $5 \mathrm{~Hz}$ stimulationinduced E-S potentiation does not involve I-LTD, EPSP/burst pairing did not decrease IPSP amplitude ( $p=0.465$ compared with baseline at 20 min after pairing) (Fig. 9B). Although EPSP/burst pairing did not significantly increase EPSP slope $(p=0.208)$ or half-width $(p=0.418)$ (Fig. 9B, C), there was a small but significant increase in peak EPSP amplitude ( $p=0.028)$ (Fig. $9 C$ ). These findings support the conclusion that $5 \mathrm{~Hz}$ stimulation-induced $\mathrm{E}-\mathrm{S}$ potentiation does not involve a lasting decrease in inhibitory synaptic transmission but instead arises from a change in intrinsic excitability that selectively boosts EPSP amplitude.

\section{Discussion}

Studies of the cellular mechanisms underlying memory formation have long focused on activity-dependent changes in excitatory synaptic strength. Although it now seems clear that synaptic plasticity has a crucial role in learning and memory formation (Morris et al., 2003; Maren, 2005), activity-dependent changes in neuronal excitability are likely to have an equally important role. Indeed, some of the most robust effects of behavioral learning on neuronal physiology involve persistent changes in intrinsic excitability (for review, see Zhang and Linden, 2003; Kim and Linden, 2007). Compared with synaptic plasticity, however, relatively little is known about the mechanisms underlying activity-dependent changes in neuronal excitability.

Using a stimulation protocol that mimics patterns of neuronal activity observed in vivo (brief bouts of theta frequency activity and postsynaptic complex spike bursting), we find that E-S potentiation is readily induced in hippocampal CA1 pyramidal
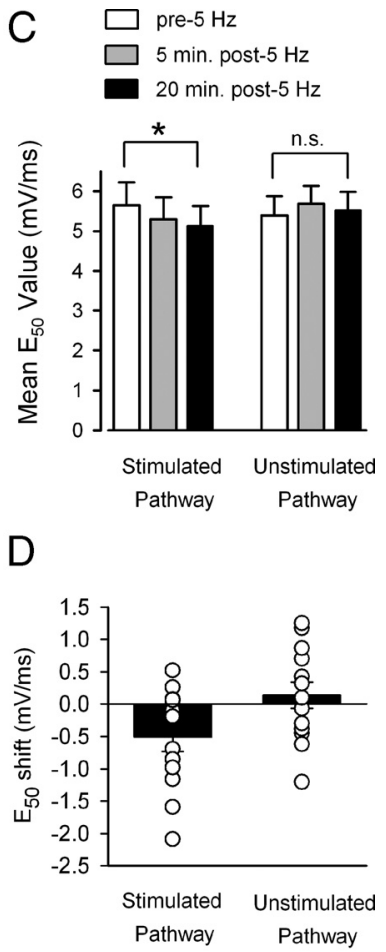

Figure 6. Three seconds of EPSP/postsynaptic burst pairing at $5 \mathrm{~Hz}$ induces an input-specific increase in excitability in CA1 列 列 $p=0.508 ; n=13) . D$, Summary of $E-S$ shift magnitude in the stimulated and unstimulated pathway. Scatter plots represent $\mathrm{E}-\mathrm{S}$ shifts from individual experiments, and error bars represent mean \pm SEM for each dataset.

cells. Importantly, this E-S potentiation can be induced by a broad window of theta frequency stimulation, in contrast to the relatively narrow durations of stimulation required for induction of synaptic LTP, indicating a distinct set of rules and mechanisms for induction. Moreover, E-S potentiation induced by $5 \mathrm{~Hz}$ stimulation exhibits a number of novel properties. First, it is induced by very modest patterns of synaptic stimulation, requiring just $2-3 \mathrm{~s}$ of $5 \mathrm{~Hz}$ presynaptic fiber stimulation (10-15 stimulation pulses). Second, E-S potentiation occurs in the absence of lasting changes in excitatory or inhibitory synaptic transmission. Finally, although this form of E-S potentiation does show properties of "Hebbian" plasticity, being both NMDA receptor dependent and input specific, the mechanisms underlying synaptic LTP and $5 \mathrm{~Hz}$ stimulation-induced E-S potentiation are distinct. For example, whereas PKA, ERK1/2, and PI3 kinase are involved in $5 \mathrm{~Hz}$ stimulation-induced synaptic LTP (Winder et al., 1999; Watabe et al., 2000; Opazo et al., 2003; Makhinson et al., 2006), inhibitors of these kinases have no effect on $5 \mathrm{~Hz}$ stimulation-induced E-S potentiation. Indeed, this E-S potentiation was resistant to even high concentrations of the broad-spectrum protein kinase inhibitor staurosporine that also blocks CaMKII and PKC, kinases that are essential for most forms of LTP. These results suggest that this form of plasticity is protein kinase independent. Consistent with this, we find that $5 \mathrm{~Hz}$ stimulation-induced $\mathrm{E}-\mathrm{S}$ potentiation is blocked by $\mathrm{PP} 2 \mathrm{~B}$ inhibitors, indicating that this form of plasticity is dependent on protein phosphatase activity. It remains to be determined whether the $\mathrm{E}-\mathrm{S}$ potentiation is attributable to direct 

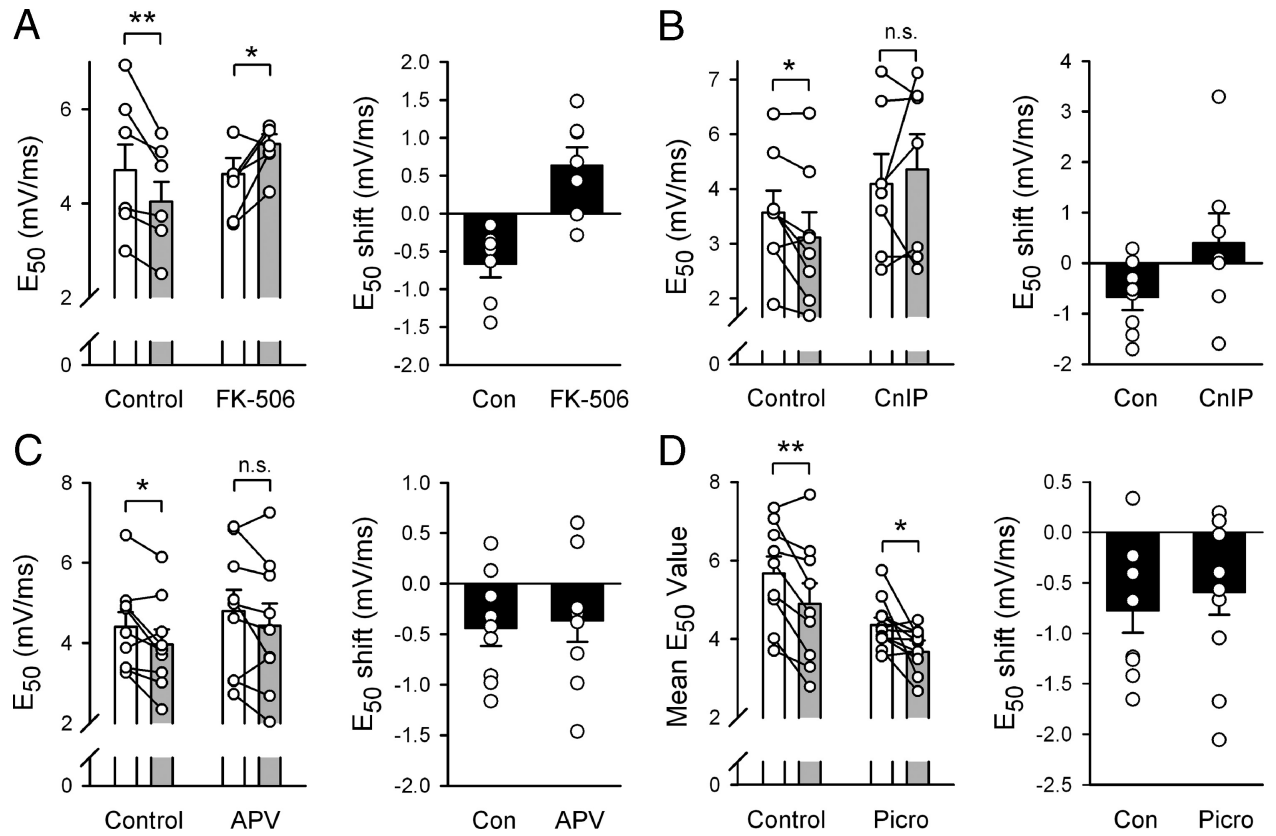

Figure 7. The EPSP/burst pairing-induced increase in excitability is blocked by calcineurin inhibitors and is insensitive to picrotoxin. All panels: Left, $E_{50}$ values before (open bars) and after ( $5 \mathrm{~Hz}$ for $3 \mathrm{~s}$; filled bars) EPSP/burst pairing. Points show values from individual experiments. Right, Summary of E-S shift magnitudes. Scatter plots represent E-S shifts from individual experiments, and error bars represent mean \pm SEM for each dataset. $A, E_{50}$ values 20 min after EPSP/burst pairing were not decreased in cells from slices bathed in ACSF containing FK-506 (20 $\left.\mu \mathrm{m} ; n=7\right)$. Instead, $E_{50}$ values were significantly increased compared with pre-pairing values, indicating a pairing-induced decrease in excitability in FK-506-treated cells. $E_{50}$ values were significantly decreased in interleaved vehicle control experiments $\left({ }^{* *} p<0.01 ; n=7\right)$. $\boldsymbol{B}$, No significant $\mathrm{E}-\mathrm{S}$ shift after EPSP/burst pairing was observed in cells in which the electrode solution contained the CnIP ( $250 \mu \mathrm{M}$; $n=7 ; p=0.513$ ), whereas $E_{50}$ values were significantly decreased in interleaved vehicle control experiments ( $\left.{ }^{*} p<0.05 ; n=8\right) . C, E_{50}$ values 20 min after EPSP/burst pairing (filled bars) were not significantly different from pre-pairing values (open bars) in cells in which slices were bathed in ACSF containing $50 \mu \mathrm{M} \mathrm{D}-\mathrm{APV}(p=0.127 ; n=9)$ but were significantly reduced in interleaved control cells ( $\left.{ }^{*} p<0.05 ; n=9\right) . \boldsymbol{D}$, EPSP/burst pairing induces a significant decrease in $E_{50}$ values even in cells bathed in ACSF containing $100 \mu \mathrm{m}$ picrotoxin ( ${ }^{*} p<0.05$ compared with pre-pairing $E_{50}$ values; $\left.n=11\right)$. A pairing-induced decrease in $E_{50}$ values was also seen in interleaved control experiments $\left({ }^{* *} p<0.01 ; n=9\right)$.
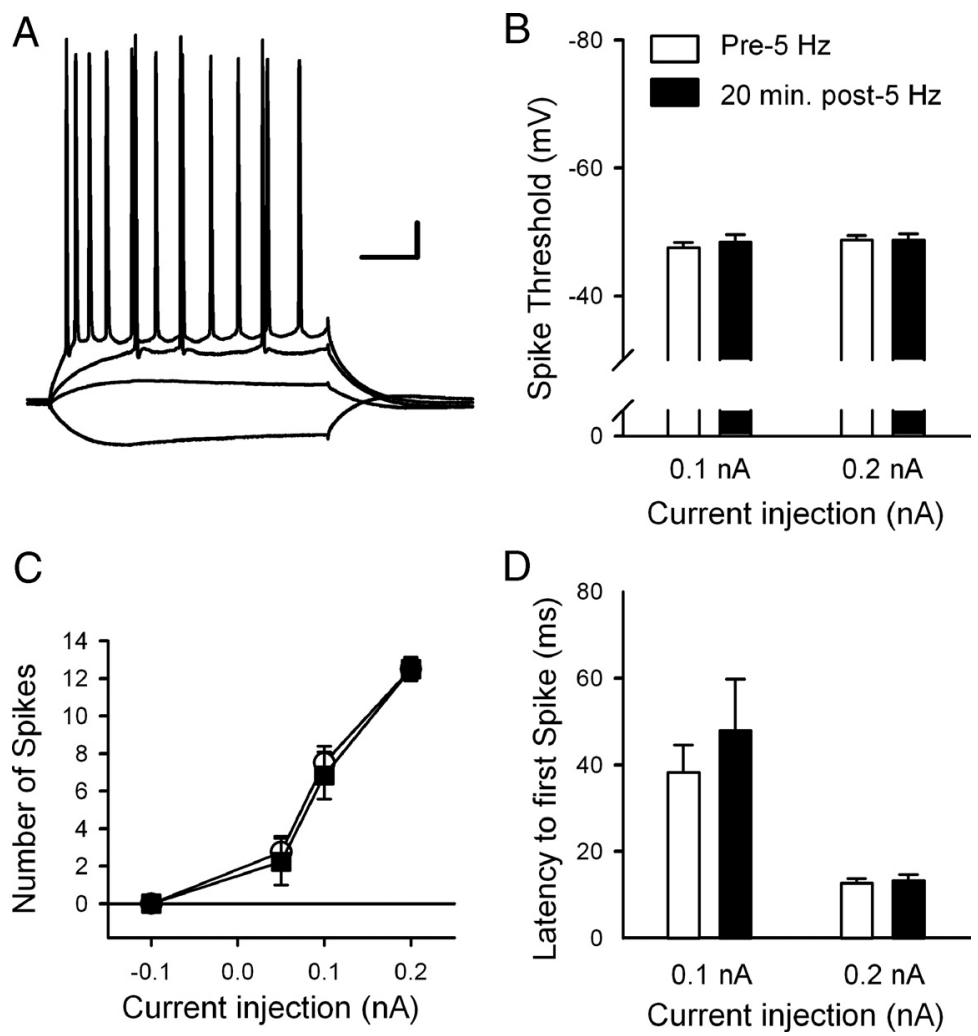

Figure 8. EPSP/burst pairing does not change intrinsic excitability measured at the soma. $A$, Examples of responses evoked by the four, 250 -ms-long current pulses $(-0.1,+0.05,+0.1$, and $+0.2 \mathrm{nA})$ used to measure postsynaptic excitability. Calibration: $50 \mathrm{~ms}, 10 \mathrm{mV}$. $\boldsymbol{B}-\boldsymbol{E}$, Twenty minutes after EPSP/burst pairing (15 pairs at $5 \mathrm{~Hz} ; n=6$ ), there is no significant change in action potential firing threshold $(\boldsymbol{B})$, number of spikes fired $(\boldsymbol{C})$, latency to the first spike $(\boldsymbol{D})$, or input resistance $(\boldsymbol{E})$. effects of PP2B or whether activation of protein phosphatase 1 by $\mathrm{PP} 2 \mathrm{~B}$ is also involved.

Cellular and molecular mechanisms of $5 \mathrm{~Hz}$ stimulation-induced E-S potentiation

Some studies have concluded that E-S potentiation is likely attributable to I-LTD (Chavez-Noriega et al., 1989; Lu et al., 2003), based in part on their findings that $\mathrm{E}-\mathrm{S}$ potentiation is absent in slices bathed in $\mathrm{GABA}_{\mathrm{A}}$ receptor blockers. Although our extracellular recordings initially suggested that $5 \mathrm{~Hz}$ stimulation-induced $\mathrm{E}-\mathrm{S}$ potentiation is disrupted by the $\mathrm{GABA}_{\mathrm{A}}$ receptor blocker picrotoxin, we noted that facilitation of PS amplitudes and bursting during $5 \mathrm{~Hz}$ stimulation was strongly disrupted in disinhibited slices. This suggests that blocking inhibition might inhibit the induction of $\mathrm{E}-\mathrm{S}$ potentiation by $5 \mathrm{~Hz}$ stimulation rather than occlude its expression. Indeed, simply doubling the intensity of presynaptic fiber stimulation during $5 \mathrm{~Hz}$ stimulation so that EPSPs elicited postsynaptic bursting rescued E-S potentiation in the presence of picrotoxin. Although not statistically significant, the amount of E-S potentiation induced by strong $5 \mathrm{~Hz}$ stimulation in picrotoxin- 

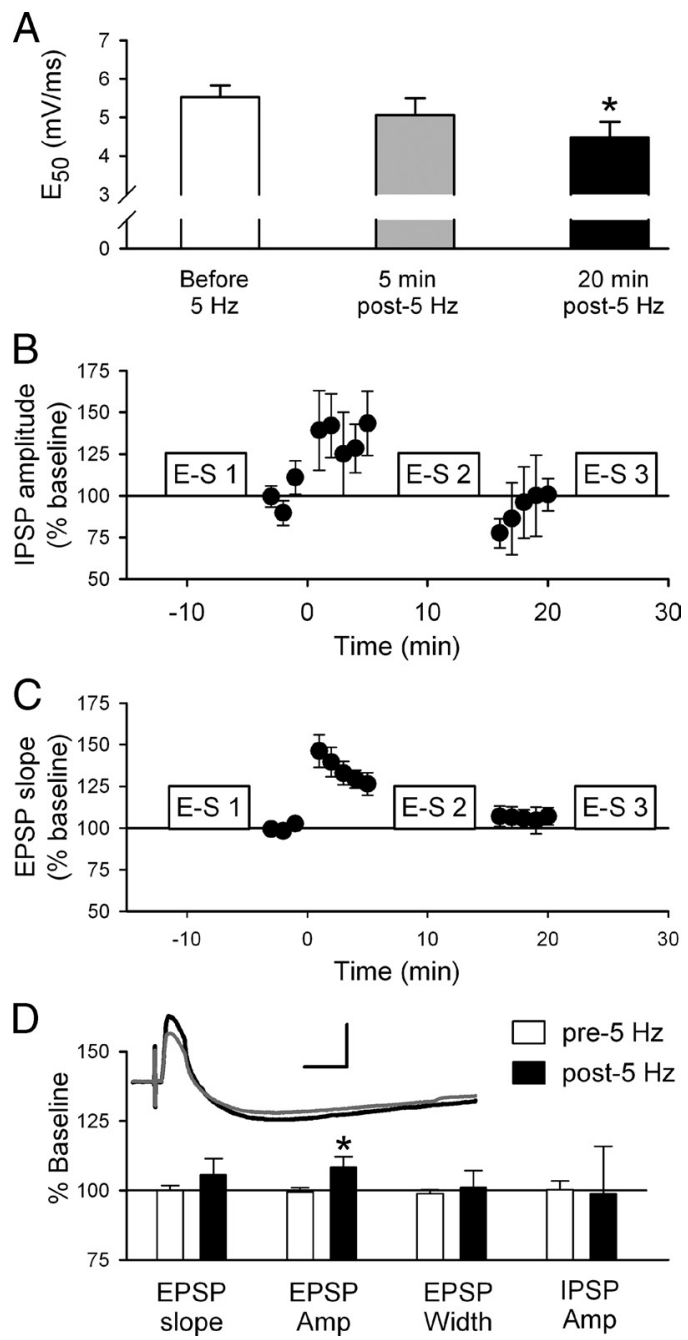

Figure 9. EPSP/burst pairing does not induce I-LTD. $A$, EPSP/burst pairing ( 15 pairs at $5 \mathrm{~Hz}$ ) induces a significant decrease in $E_{50}$ values 20 min after pairing $(n=13) . \boldsymbol{B}-\boldsymbol{D}$, Measurements of EPSPs and IPSPs between E-S curves from the cells shown in $\boldsymbol{A}$. EPSP and IPSP measurements were taken before, $0-5 \mathrm{~min}$ after, and 15-20 min after pairing. EPSP/burst pairing has no lasting effect on IPSP amplitude (B) or EPSP slope (C). D, Summary of EPSP and IPSP characteristics before and $20 \mathrm{~min}$ after EPSP/burst pairing ${ }^{*} p<0.05$, all comparisons made using one-tailed paired $t$ tests). The inset shows an example of postsynaptic responses elicited before (gray) and $20 \mathrm{~min}$ after (black) EPSP/burst pairing. Calibration: $20 \mathrm{~ms}, 5 \mathrm{mV}$.

treated slices was somewhat less than that seen in control experiments. Based on this finding alone, it is thus difficult to rule out the possibility that changes in both inhibitory synaptic transmission and intrinsic excitability might contribute to $5 \mathrm{~Hz}$ stimulation-induced E-S potentiation as has been suggested for E-S potentiation induced by other forms of synaptic stimulation (Staff and Spruston, 2003). However, in other experiments, we also observed that pairing EPSPs evoked during $5 \mathrm{~Hz}$ stimulation with bursts of postsynaptic action potentials had no lasting effect on IPSPs. Thus, it appears likely that changes in intrinsic excitability are primarily responsible for the expression of $5 \mathrm{~Hz}$ stimulation-induced $\mathrm{E}-\mathrm{S}$ potentiation. It is interesting, however, that blocking $\mathrm{GABA}_{\mathrm{A}}$-mediated inhibition suppressed the induction of $5 \mathrm{~Hz}$ stimulation-induced E-S potentiation. One likely explanation is that the transient activity-dependent depression of inhibitory synaptic transmission that occurs during theta frequency stimulation (Davies et al., 1991; Mott and Lewis, 1991) facilitates postsynaptic bursting during $5 \mathrm{~Hz}$ stimulation, thus providing the depolarization needed for NMDA receptor activation and the induction of $\mathrm{E}-\mathrm{S}$ potentiation. In the presence of picrotoxin, this activity-dependent downregulation of inhibition is occluded, and thus postsynaptic bursting is not elicited during $5 \mathrm{~Hz}$ stimulation by weak intensities of presynaptic fiber stimulation.

Is the blockade of $\mathrm{E}-\mathrm{S}$ potentiation by $\mathrm{GABA}_{\mathrm{A}}$ inhibitors observed in previous studies attributable to disruptions of induction or expression? One would expect induction to be most disrupted by $\mathrm{GABA}_{\mathrm{A}}$ blockade in studies using protocols that, like $5 \mathrm{~Hz}$ stimulation, depend on frequency-dependent disinhibition. High-frequency stimulation protocols, in contrast, are unlikely to rely on disinhibition to induce plasticity. Importantly, previous studies have directly demonstrated plasticity of inhibitory synaptic transmission onto CA1 pyramidal cells (Lu et al., 2000; Shew et al., 2000; Chevaleyre and Castillo, 2003) or plasticity at excitatory synapses onto interneurons (Taube and Schwartzkroin, 1987; Ouardouz and Lacaille, 1995; McMahon and Kauer, 1997; Cowan et al., 1998). Thus, it seems clear that I-LTD can make an important contribution to $\mathrm{E}-\mathrm{S}$ potentiation induced by some forms of synaptic stimulation. Our results indicate, however, that I-LTD does not contribute to E-S potentiation induced by theta frequency patterns of synaptic stimulation and suggest that careful interpretation is needed when blocking channels, such as $\mathrm{GABA}_{\mathrm{A}}$ receptors, that are essential components of basal circuit functions as well as potential targets for plasticity.

Overall, the fact that $5 \mathrm{~Hz}$ stimulation-induced $\mathrm{E}-\mathrm{S}$ potentiation is both input specific and picrotoxin insensitive indicates that this form of plasticity is, at least in part, attributable to local changes in intrinsic excitability. Consistent with this, we find that pairing presynaptic $5 \mathrm{~Hz}$ stimulation with bursts of postsynaptic action potentials induced $\mathrm{E}-\mathrm{S}$ potentiation without any change in several measures of somatic excitability. We did, however, observe that $5 \mathrm{~Hz}$ stimulation-induced E-S potentiation was associated with a selective increase in EPSP amplitude with no lasting changes in IPSPs. Although we cannot rule out potential changes in AMPA receptor kinetics that might mediate this effect, the absence of a significant change in the rising slope or width of the EPSP seems inconsistent with a change in AMPA receptor function. Moreover, $5 \mathrm{~Hz}$ stimulation-induced E-S potentiation is dependent on PP2B activity, whereas dephosphorylation of AMPA receptors is associated with downregulation of channel activity and/or receptor internalization (for review, see Lee, 2006). The precise cellular changes responsible for the expression of $5 \mathrm{~Hz}$ stimulation-induced E-S potentiation, however, remain unclear. Previous studies have identified a number of activitydependent and input-specific changes in the activity of dendritic voltage-gated ion channels that could be involved (Frick et al., 2004; Campanac and Debanne, 2008; Losonczy et al., 2008). Notably, Losonczy et al. (2008) demonstrated a form of activitydependent plasticity that governs the output of individual dendritic branches through downregulation of A-type potassium channels. The E-S potentiation that we observe might be mediated by similar changes in the properties of voltage-gated ion channels. Importantly, although future dendritic recordings will be needed to identify the channel modifications involved in $5 \mathrm{~Hz}$ stimulation-induced E-S potentiation, our results suggest that changes downstream of PP2B-dependent dephosphorylation are likely to have a key role. For example, activation of CaMKII can trigger the membrane insertion of A-type potassium channels in hippocampal pyramidal cells (Varga et al., 2004), and thus one possibility is that a $\mathrm{PP} 2 \mathrm{~B}$-mediated reversal of this process could lead to an increase in excitability. Moreover, because both 
voltage-activated sodium channels and some types of voltageactivated calcium channels in hippocampal neurons are downregulated by phosphorylation (Cantrell et al., 1999; Yasuda et al., 2003; Chen et al., 2005), $5 \mathrm{~Hz}$ stimulation-induced changes in the activity of these channels are also likely candidates for future studies.

\section{Significance of $5 \mathrm{~Hz}$ stimulation-induced E-S potentiation}

Previous work has shown that genetic deletion of calcineurin impairs hippocampal-dependent learning in mice (Zeng et al., 2001). Although this is usually thought to demonstrate the importance of synaptic LTD in learning, our results suggest that the behavioral phenotypes in these mutant mice might, at least in part, be attributable to disruption of local increases in excitability that occur in $5 \mathrm{~Hz}$ stimulation-induced $\mathrm{E}-\mathrm{S}$ potentiation. Indeed, compartmentalized regulation of intrinsic excitability can significantly boost the information storage capacity of highly arborized neurons (Häusser et al., 2000; Poirazi and Mel, 2001; Häusser and Mel, 2003; Polsky et al., 2004). Given the large and long-lasting increase in PS amplitudes, $5 \mathrm{~Hz}$ stimulation-induced E-S potentiation might also strongly enhance NMDA receptor activation by subsequent patterns of synaptic activity. This form of E-S potentiation may thus not only contribute to the encoding of information during memory formation but also act as a form of metaplasticity (Abraham, 2008) that regulates the induction of synaptic LTP and LTD.

\section{References}

Abraham WC (2008) Metaplasticity: tuning synapses and networks for plasticity. Nat Rev Neurosci 9:387-399.

Abraham WC, Gustafsson B, Wigström H (1987) Long-term potentiation involves enhanced synaptic excitation relative to synaptic inhibition in guinea-pig hippocampus. J Physiol 394:367-380.

Andersen P, Sundberg SH, Sveen O, Swann JW, Wigström H (1980) Possible mechanisms for long-lasting potentiation of synaptic transmission in hippocampal slices from guinea-pigs. J Physiol 302:463-482.

Bekkers JM, Delaney AJ (2001) Modulation of excitability by $\alpha$-dendrotoxinsensitive potassium channels in neocortical pyramidal neurons. J Neurosci 21:6553-6560.

Bliss TV, Lomo T (1973) Long-lasting potentiation of synaptic transmission in the dentate area of the anaesthetized rabbit following stimulation of the perforant path. J Physiol 232:331-356.

Breakwell NA, Rowan MJ, Anwyl R (1996) Metabotropic glutamate receptor dependent EPSP and EPSP-Spike potentiation in area CA1 of the submerged rat hippocampal slice. J Neurophysiol 76:3126-3135.

Buzsáki G (2002) Theta oscillations in the hippocampus. Neuron 33: 325-340.

Campanac E, Debanne D (2008) Spike timing-dependent plasticity: a learning rule for dendritic integration in rat CA1 pyramidal neurons. J Physiol 586:779-793

Cantrell AR, Scheuer T, Catterall WA (1999) Voltage-dependent neuromodulation of $\mathrm{Na}^{+}$channels by D1-like dopamine receptors in rat hippocampal neurons. J Neurosci 19:5301-5310.

Chavez-Noriega LE, Bliss TV, Halliwell JV (1989) The EPSP-spike (E-S) component of long-term potentiation in the rat hippocampal slice is modulated by GABAergic but not cholinergic mechanisms. Neurosci Lett 104:58-64.

Chen QX, Stelzer A, Kay AR, Wong RKS (1990) GABA $_{\mathrm{A}}$ receptor function is regulated by phosphorylation in acutely dissociated guinea-pig hippocampal neurones. J Physiol 420:207-221.

Chen Y, Cantrell AR, Messing RO, Scheuer T, Catterall WA (2005) Specific modulation of $\mathrm{Na}^{+}$channels in hippocampal neurons by protein kinase C. J Neurosci 25:507-513.

Chevaleyre V, Castillo PE (2003) Heterosynaptic LTD of hippocampal GABAergic synapses: a novel role of endocannabinoids in regulating excitability. Neuron 38:461-472.

Chevaleyre V, Castillo PE (2004) Endocannabinoid-mediated metaplasticity in the hippocampus. Neuron 43:871-881.
Cowan AI, Stricker C, Reece LJ, Redman SJ (1998) Long-term plasticity at excitatory synapses on aspinous interneurons in area CA1 lacks synaptic specificity. J Neurophysiol 79:13-20.

Cudmore RH, Turrigiano GG (2004) Long-term potentiation of intrinsic excitability in LV visual cortical neurons. J Neurophysiol 92:341-348.

Daoudal G, Hanada Y, Debanne D (2002) Bidirectional plasticity of excitatory postsynaptic potential (EPSP)-spike coupling in CA1 hippocampal pyramidal neurons. Proc Natl Acad Sci U S A 99:14512-14517.

Davies CH, Starkey SJ, Pozza MF, Collingridge GL (1991) GABA $_{B}$ autoreceptors regulate the induction of LTP. Nature 349:609-611.

Fan Y, Fricker D, Brager DH, Chen X, Lu HC, Chitwood RA, Johnston D (2005) Activity-dependent decrease of excitability in rat hippocampal neurons through increases in I(h). Nat Neurosci 8:1542-1551.

Frick A, Magee J, Johnston D (2004) LTP is accompanied by an enhanced local excitability of pyramidal neuron dendrites. Nat Neurosci 7:126-135.

Hagiwara N, Irisawa H (1989) Modulation by intracellular $\mathrm{Ca}^{2+}$ of the hyperpolarization-activated inward current in rabbit single sino-atrial node cells. J Physiol 409:121-141.

Häusser M, Mel B (2003) Dendrites: bug or feature? Curr Opin Neurobiol 13:372-383.

Häusser M, Spruston N, Stuart GJ (2000) Diversity and dynamics of dendritic signaling. Science 290:739-744.

Hess G, Gustafsson B (1990) Changes in field excitatory postsynaptic potential shape induced by tetanization in the CA1 region of the guinea-pig hippocampal slice. Neuroscience 37:61-69.

Jester JM, Campbell LW, Sejnowski TJ (1995) Associative EPSP-spike potentiation induced by pairing orthodromic and antidromic stimulation in rat hippocampal slices. J Physiol 484:689-705.

Kim SJ, Linden DJ (2007) Ubiquitous plasticity and memory storage. Neuron 56:582-592.

Lee HK (2006) Synaptic plasticity and phosphorylation. Pharmacol Therapeutics 12:810-832.

Ling DS, Benardo LS, Serrano PA, Blace N, Kelly MT, Crary JF, Sacktor TC (2002) Protein kinase $M \zeta$ is necessary and sufficient for LTP maintenance. Nat Neurosci 5:295-296.

Losonczy A, Makara JK, Magee JC (2008) Compartmentalized dendritic plasticity and input feature storage in neurons. Nature 452:436-441.

Lu YM, Mansuy IM, Kandel ER, Roder J (2000) Calcineurin-Mediated LTD of GABA-ergic inhibition underlies the increased excitability of CA1 neurons associated with LTP. Neuron 26:197-205.

Makhinson M, Opazo P, Carlisle HJ, Godsil B, Grant SG, O’Dell TJ (2006) A novel role for cyclic guanosine $3^{\prime}, 5^{\prime}$ monophosphate signaling in synaptic plasticity: a selective suppressor of protein kinase A-dependent forms of long-term potentiation. Neuroscience 140:415-431.

Marder CP, Buonomano DV (2003) Differential effects of short- and longterm potentiation on cell firing in the CA1 region of the hippocampus. J Neurosci 23:112-121.

Marder CP, Buonomano DV (2004) Timing and balance of inhibition enhance the effect of long-term potentiation on cell firing. J Neurosci 24:8873-8884.

Maren S (2005) Synaptic mechanisms of associative memory in the amygdala. Neuron 47:783-786.

McMahon LL, Kauer JA (1997) Hippocampal interneurons express a novel form of synaptic plasticity. Neuron 18:295-305.

Morris RG, Moser EI, Riedel G, Martin SJ, Sandin J, Day M, O'Carroll C (2003) Elements of a neurobiological theory of the hippocampus: the role of activity-dependent synaptic plasticity in memory. Philos Trans R Soc Lond B Biol Sci 358:773-786.

Mott DD, Lewis DV (1991) Facilitation of the induction of long-term potentiation by GABAB receptors. Science 252:1718-1720.

Mulkey RM, Herron CE, Malenka RC (1993) An essential role for protein phosphatases in hippocampal long-term depression. Science 261:1051-1055.

Mulkey RM, Endo S, Shenolikar S, Malenka RC (1994) Involvement of a calcineurin/inhibitor-1 phosphatase cascade in hippocampal long-term depression. Nature 369:486-488.

Opazo P, Watabe AM, Grant SG, O’Dell TJ (2003) Phosphatidylinositol 3-kinase regulates the induction of long-term potentiation through extracellular signal-related kinase-independent mechanisms. J Neurosci 23:3679-3688.

Ouardouz M, Lacaille JC (1995) Mechanisms of selective long-term poten- 
tiation of excitatory synapses in stratum oriens/alveus interneurons of rat hippocampal slices. J Neurophysiol 73:810-819.

Poirazi P, Mel BW (2001) Impact of active dendrites and structural plasticity on the memory capacity of neural tissue. Neuron 29:779-796.

Polsky A, Mel BW, Schiller J (2004) Computational subunits in thin dendrites of pyramidal cells. Nat Neurosci 7:621-627.

Ranck JB Jr (1973) Studies on single neurons in dorsal hippocampal formation and septum in unrestrained rats. I. Behavioral correlates and firing repertoires. Exp Neurol 41:461-531.

Shew T, Yip S, Sastry BR (2000) Mechanisms involved in tetanus-induced potentiation of fast IPSCs in rat hippocampal CA1 neurons. J Neurophysiol 83:3388-3401.

Spruston N (2008) Pyramidal neurons: dendritic structure and synaptic integration. Nat Rev Neurosci 9:206-221.

Staff NP, Spruston N (2003) Intracellular correlate of EPSP-Spike potentiation in CA1 pyramidal neurons is controlled by GABAergic modulation. Hippocampus 13:801-805.

Taube JS, Schwartzkroin PA (1987) Intracellular recording from hippocampal CA1 interneurons before and after development of long-term potentiation. Brain Res 419:32-38.

Thomas MJ, Moody TD, Makhinson M, O’Dell TJ (1996) Activitydependent beta-adrenergic modulation of low frequency stimulation induced LTP in the hippocampal CA1 region. Neuron 17:475-482.

Thomas MJ, Watabe AM, Moody TD, Makhinson M, O’Dell TJ (1998) Postsynaptic complex spike bursting enables the induction of LTP by theta frequency synaptic stimulation. J Neurosci 18:7118-7126.

Varga AW, Yuan LL, Anderson AE, Schrader LA, Wu GY, Gatchel JR,
Johnston D, Sweatt JD (2004) Calcium-calmodulin-dependent kinase II modulates Kv4.2 channel expression and upregulates neuronal A-type potassium currents. J Neurosci 24:3643-3654.

Velumian AA, Carlen PL (1999) Differential control of three afterhyperpolarizations in rat hippocampal neurones by intracellular calcium buffering. J Physiol 517:201-216.

Watabe AM, Zaki PA, O’Dell TJ (2000) Coactivation of beta-adrenergic and cholinergic receptors enhances the induction of long-term potentiation and synergistically activates mitogen-activated protein kinase in the hippocampal CA1 region. J Neurosci 20:5924-5931.

Winder DG, Martin KC, Muzzio IA, Rohrer D, Chruscinski A, Kobilka B, Kandel ER (1999) ERK plays a regulatory role in induction of LTP by theta frequency stimulation and its modulation by beta-adrenergic receptors. Neuron 24:715-726.

Xu J, Kang N, Jiang L, Nedergaard M, Kang J (2005) Activity-dependent long-term potentiation of intrinsic excitability in hippocampal CA1 pyramidal neurons. J Neurosci 25:1750-1760.

Yasuda R, Sabatini BL, Svoboda K (2003) Plasticity of calcium channels in dendritic spines. Nat Neurosci 6:948-955.

Zeng H, Chattarji S, Barbarosie M, Rondi-Reig L, Philpot BD, Miyakawa T, Bear MF, Tonegawa S (2001) Forebrain-specific calcineurin knockout selectively impairs bidirectional synaptic plasticity and working/episodiclike memory. Cell 107:617-629.

Zhang W, Linden DJ (2003) The other side of the engram: Experiencedriven changes in neuronal intrinsic excitability. Nat Rev Neurosci 4:885900 . 